\title{
Designing reliable silicone elastomers for high-temperature applications
}

\author{
Ogliani, Elisa; Yu, Liyun; Mazurek, Piotr ; Skov, Anne Ladegaard
}

Published in:

Polymer Degradation and Stability

Link to article, DOI:

10.1016/j.polymdegradstab.2018.10.012

Publication date:

2018

Document Version

Peer reviewed version

Link back to DTU Orbit

Citation (APA):

Ogliani, E., Yu, L., Mazurek, P., \& Skov, A. L. (2018). Designing reliable silicone elastomers for high-temperature applications. Polymer Degradation and Stability, 157, 175-180.

https://doi.org/10.1016/j.polymdegradstab.2018.10.012

\section{General rights}

Copyright and moral rights for the publications made accessible in the public portal are retained by the authors and/or other copyright owners and it is a condition of accessing publications that users recognise and abide by the legal requirements associated with these rights.

- Users may download and print one copy of any publication from the public portal for the purpose of private study or research.

- You may not further distribute the material or use it for any profit-making activity or commercial gain

- You may freely distribute the URL identifying the publication in the public portal 


\section{Accepted Manuscript}

Designing reliable silicone elastomers for high-temperature applications

Elisa Ogliani, Liyun Yu, Piotr Mazurek, Anne L. Skov

PII: $\quad$ S0141-3910(18)30324-0

DOI: $\quad$ 10.1016/j.polymdegradstab.2018.10.012

Reference: $\quad$ PDST 8661

To appear in: Polymer Degradation and Stability

Received Date: 19 July 2018

Revised Date: 19 September 2018

Accepted Date: 11 October 2018

Please cite this article as: Ogliani E, Yu L, Mazurek P, Skov AL, Designing reliable silicone elastomers for high-temperature applications, Polymer Degradation and Stability (2018), doi: https://doi.org/10.1016/ j.polymdegradstab.2018.10.012.

This is a PDF file of an unedited manuscript that has been accepted for publication. As a service to our customers we are providing this early version of the manuscript. The manuscript will undergo copyediting, typesetting, and review of the resulting proof before it is published in its final form. Please note that during the production process errors may be discovered which could affect the content, and all legal disclaimers that apply to the journal pertain. 


\section{Designing reliable silicone elastomers for high-}

\section{temperature applications}

Elisa Ogliani, Liyun Yu, Piotr Mazurek, Anne L. Skov*

Danish Polymer Centre, Department of Chemical Engineering, Technical University of

Denmark, Søltofts Plads, 2800 Kgs. Lyngby, Denmark.

Table of Contents

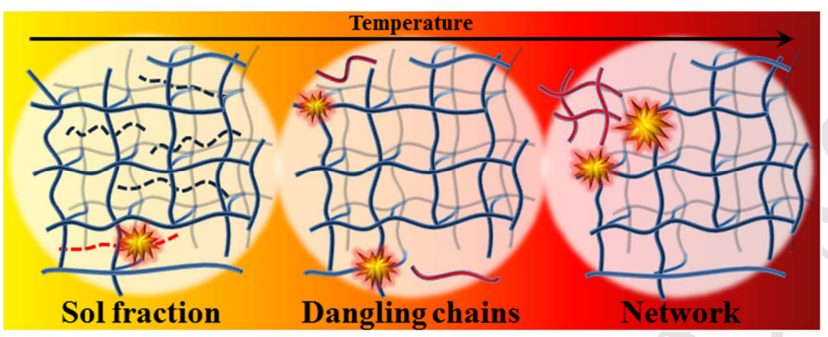

\section{ABSTRACT}

Reliability and durability are strict requirements for silicone elastomers employed in hightemperature applications, if long-time device performance is desired. Improving the thermal stability of silicone elastomers is a major challenge, addressed by both the scientific and the industrial community. Nevertheless, traditional methods such as adding heat-resistant fillers or chemical modifications still suffer from considerable shortcomings. Here, it is demonstrated that the thermal degradation behavior of silicone elastomers is affected strongly by network reactant stoichiometry. Comparative thermal degradation studies were performed on silicone elastomers synthesized with different stoichiometric ratios_-and thereby different 
fractions of elastic, dangling, and sol structures. With the reported findings, we demonstrate how to optimize the stoichiometric ratio used to prepare silicone elastomers, in order to enhance their thermal stability by simple means in high-temperature applications.

KEYWORDS Thermal stability, thermal degradation mechanisms, silicone elastomers.

\section{INTRODUCTION}

Modern people experience increasingly more inspiring uses of silicone elastomers, such as soft robotics [1] ranging from millibots [2] to large humanoids [3], as well as electronic skin with sensing properties and diagnostic functions [4,5]. Silicone elastomers are also used in more well-established technologies such as those found in the automotive [6] and the aerospace [7] industries, biomedical implants [8], microfluidic devices [9], and microelectromechanical systems (MEMSs) [10]. The versatility of silicone elastomers is illustrated by the wide range of product sizes, ranging from the delicate components of microsensors [11], to robust, multi-ton dielectric elastomer generators for offshore energy harvesting [12]. This usefulness across scales and in different environments derives from the combination of structural properties of the siloxane backbone [13]. In particular, high dissociation energy and a low energy barrier to siloxane bond rotation [14] provide silicones with remarkable thermal stability. Therefore, silicone-based materials—and in particular silicone elastomers-are suitable for high-temperature applications such as protective coatings [15], encapsulants in light-emitting diodes (LED) [16], insulators for electric cables [17], heat-shielding materials for solid rocket motors [18], and commodities such as baking molds. In a silicone elastomer, crosslinking a telechelic functionalized silicone polymer into networks furthermore provides dimensional stability, elasticity, and flexibility. One of the most common methods to facilitate crosslinking is additional curing of the silicone, the reaction of which is characterized by high yields and insignificant numbers of side reactions. 
Therefore, well-defined networks can be formed whereby the individual polymer strands will be elastic (i.e. linked to the infinite network at both ends), dangling (i.e. linked at one end only), or part of the sol (not linked to the infinite network) [19-21]. By controlling stoichiometry (the ratio of crosslinking functional groups to polymer functional groups) the relative fractions of network structures can be changed, and by using a small excess of highfunctional crosslinker, most of the polymer strands can be made elastic [22].

Among silicones, the most commonly used polymer is polydimethylsiloxane (PDMS). It is essential to understand its thermal degradation behavior, in order to satisfy successfully the requirements of durability, reliability, and non-toxicity over a wide range of environmental changes such as elevated temperatures. Previous studies have elucidated some of the underlying mechanisms [23-25]; for instance, when a linear PDMS polymer, either as an oil or incorporated into an elastomer, is exposed to elevated temperatures, different degradation mechanisms occur [26] and, consequently, volatile cyclic oligomers are released and crosslinking reactions may take place. These structural rearrangements lead to an irreversible and undesired change in the chemical and physical properties of the material. A main implication of so-called "thermal ageing" is increased susceptibility to fracturing and tearing [27]. Moreover, changes in properties over time can also be observed from the evaporation of residual solvent. Therefore, silicone elastomers intended for high-temperature uses are usually subjected to a post-curing treatment, in order to limit the outgassing of volatiles at the operating temperature, which can lead to bubbling or delamination of the silicone component in the device. During post-curing, volatiles are removed from the silicone elastomers by diffusion and evaporation at a higher temperature than the curing temperature [28], and this results in increased Young's moduli [29]. Post-curing, however, is an additional and expensive procedure, and it is thus preferably avoided in manufacturing processes. 
Due to the increasing demand of high-performance silicone elastomers, significant scientific and industrial effort has been put into improving their thermal stability. One common way to progress thermal stability is to add heat-resistant fillers into the formulations, such as $\mathrm{CaCO}_{3}$ [30], platinum [31], and carbon nanotubes [32]. However, poor filler compatibility with the matrix and loss of transparency are often significant drawbacks. An alternative approach consists of grafting specialized functionalities, e.g. polyhedral oligomeric silsesquioxanes (POSS), onto the silicone network to enhance heat resistance [33]. Nevertheless, a chemical modification of the silicone network renders the product more expensive, which is thus not necessarily appealing at an industrial level. Developing cheap and easy solutions to improve the thermal stability of silicone elastomers is a major challenge, especially when also seeking to reduce the thermal ageing of silicone components, with the overall goal of increasing the lifetime and span of operation of devices.

This study focuses on determining the role of network structure on the thermal degradation of silicone elastomers, to investigate if PDMS degrades differently depending on its mobility. Consequently, elastomers with different stoichiometric ratios were synthesized to vary the relative fractions of elastic, dangling, and sol structures, with the elastic fraction having the least mobility and the sol fraction being the most mobile. Thermogravimetric analysis was used to investigate the thermal degradation of silicone networks with different crosslinking densities. Degradation products and changes in the silicone elastomers' thermal properties resulting from the treatment at high-temperatures were also analyzed. 


\section{MATERIALS AND METHODS}

\subsection{Materials}

Vinyl-terminated polydimethylsiloxane (DMS-V35, $5000 \mathrm{cSt})$ and (25-35\%

methylhydrosiloxane)-dimethylsiloxane copolymer, trimethylsiloxane terminated (HMS-301, 25-35 cSt) were purchased from Gelest. Platinum(0)-1,3-divinyl-1,1,3,3tetramethyldisiloxane complex solution (catalyst 511, Pt 1\%) was supplied by Hanse Chemie AG, while heptane (Sigma-Aldrich, 95\%) and toluene (Sigma-Aldrich, 99.8\%) were used as received.

\subsection{Synthesis of the silicone elastomers}

Silicone elastomers were synthesized via a hydrosilylation reaction between the vinylterminated polydimethylsiloxane DMS-V35 (denoted V35, $\mathrm{M}_{\mathrm{w}}=52900 \mathrm{~g} / \mathrm{mol}$, as determined by SEC) and the hydride-functional crosslinker HMS-301 (f=8, $\mathrm{M}_{\mathrm{w}}=1900 \mathrm{~g} / \mathrm{mol}$, as determined by NMR and SEC, respectively), catalyzed by platinum (Karstedt's catalyst, 511). PDMS, crosslinker, and catalyst were mixed uniformly, using a dual asymmetric centrifuge (SpeedMixer DAC 150 FVZ-Kat) at $3000 \mathrm{rpm}$ for 2 minutes. The uniform mixture was cast on a mold with a $1 \mathrm{~mm}$ spacer and cured in an oven at $80^{\circ} \mathrm{C}$ for 3 days, to ensure the maximum conversion. Three formulations with different stoichiometric imbalances (molar ratio of hydrosilane groups over vinyl groups, $r=1,1.5,2$ ) were prepared, in order to obtain silicone networks with different crosslinking densities. Subsequently, unreacted PDMS (sol fraction) was removed from the silicone elastomers by extraction in heptane for 24 hours. The extracted samples were dried at room temperature and then placed in the oven at $60^{\circ} \mathrm{C}$ for 4 hours, to remove the solvent completely. Samples were weighed before and after extraction, in order to determine the sol fractions. 


\subsection{Thermogravimetry analysis (TGA)}

Thermogravimetry analysis was performed on a thermogravimetric analyzer Discovery series (TA instruments). Samples ( 10 mg) were heated in a platinum pan from room temperature to $700^{\circ} \mathrm{C}$ under a nitrogen flow $\left(25 \mathrm{~mL} \mathrm{~min}^{-1}\right)$ at a heating rate of $10^{\circ} \mathrm{C} \mathrm{min}^{-1}$. Long-term thermal treatment of the samples ( $~ 80 \mathrm{mg}$ ) was carried out at constant temperatures of 300 and $400^{\circ} \mathrm{C}$, respectively, for 12 hours under nitrogen flow.

\subsection{Thermogravimetry-Fourier transform infrared spectroscopy (TG-FTIR)}

Thermogravimetry-Fourier transform infrared spectroscopy was applied to analyze the volatile degradation products of the silicone elastomers during the long-term isothermal treatments. The TG-FTIR instrument consists of the thermogravimeter, a Fourier transform infrared spectrometer (Nicolet iS10, from Thermo Fisher Scientific), and a transfer tube connecting the TG furnace and the infrared cell.

\subsection{Linear viscoelasticity (LVE) measurements}

Linear viscoelastic properties of the silicone elastomers were measured with an ARES-G2 rheometer (TA Instruments) at a controlled strain mode (1\%), in a frequency range of 100 to $0.01 \mathrm{~Hz}$, using a parallel-plate geometry (diameter of $8 \mathrm{~mm}$ ).

\subsection{Size exclusion chromatography (SEC)}

Size exclusion chromatography was run with a Shimadzu instrument equipped with two SDV linear columns assembled in series and a refractive index detector (RID-10A), utilizing toluene as the mobile phase $\left(1 \mathrm{~mL} \mathrm{~min}^{-1}\right)$ and operating at room temperature. Weight and number, respectively, average molecular weights and polydispersity indexes $\left(\bigoplus_{M}\right)$ were calculated using PDMS standards employing TriSEC software. 


\section{RESULTS AND DISCUSSION}

Series of PDMS elastomers were synthetized by means of an additional curing reaction (Fig. 1a), using three different stoichiometric imbalances $(r)$, namely $1,1.5$, and 2 , between the reactants (telechelic vinyl functional PDMS and an eight-functional hydride oligomer). Different network structures were obtained, ranging from high-content dangling PDMS chains and a substantial sol fraction (soluble species), to well-crosslinked networks with very few dangling PDMS chains and little sol fraction. When $r>1$, an excess of crosslinker is present and — theoretically_all telechelic functional PDMS chains are linked to a crosslinker at both ends. In practice, when a network is formed, a two-phase system is obtained, consisting of a network and a sol fraction, due to steric hindrance of the reaction sites on the multifunctional crosslinker. The structure of the elastomer moves closer to a fully reacted network from $r=1$ towards $r=1.5$ and 2, and both the numbers of dangling chains as well as the amounts of sol fraction decrease, in line with traditional network theory where steric hindrance of the crosslinker is taken into consideration [34]. All the networks behave as viscoelastic materials with mainly elastic origins, while a higher stoichiometric imbalance results in increased storage moduli ( $\mathrm{G}^{\prime}$ ) for the investigated range of $r$ (Fig. 2). The elastomer with $r=1$ contains a significantly larger amount of sol fraction compared to the elastomers with $r=1.5$ and 2 (the determined weight fractions of sol are $29.3 \%, 8 \%$, and $6.9 \%$, respectively, as listed in Table S1). The silicone elastomers were swelled in heptane, in order to separate the washed network from the corresponding sol fraction and to analyze the two phases. For all networks, removing the sol fraction results in an increase in $\mathrm{G}^{\prime}$ (Fig. 2). Subsequently, the non-extracted and extracted elastomers were analyzed by TGA coupled with FTIR, to evaluate their thermal degradation behavior when heated from room temperature up to $700^{\circ} \mathrm{C}$ and when exposed to long-term isothermal treatment (Fig. 1b). 
(a)

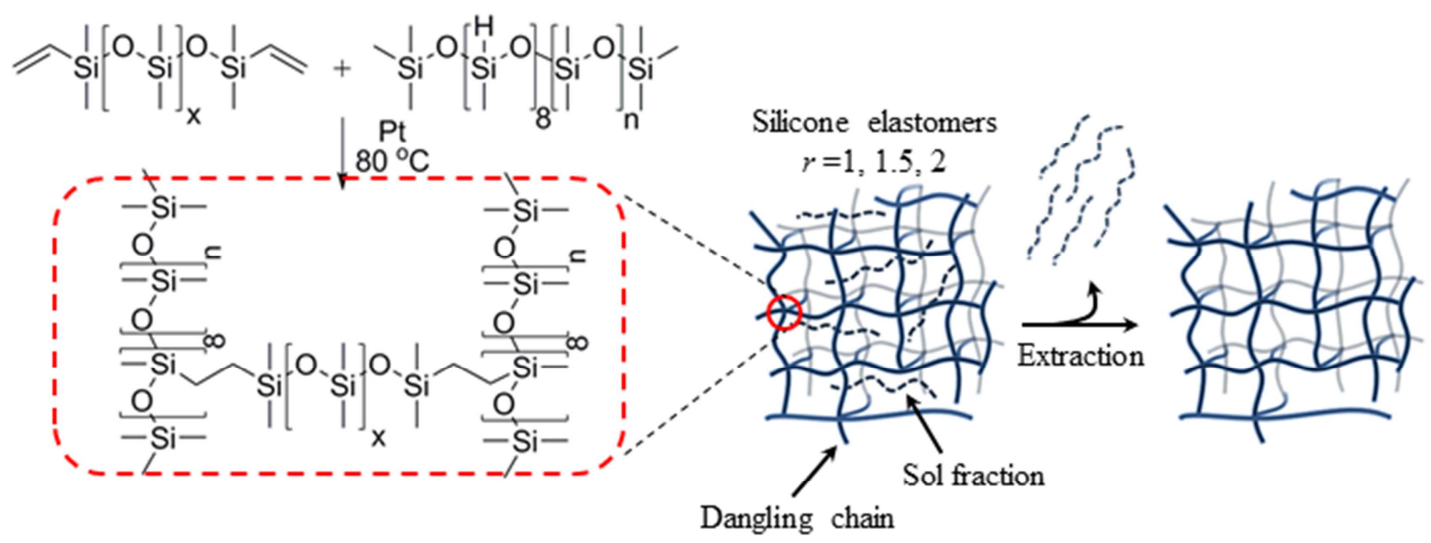

(b)

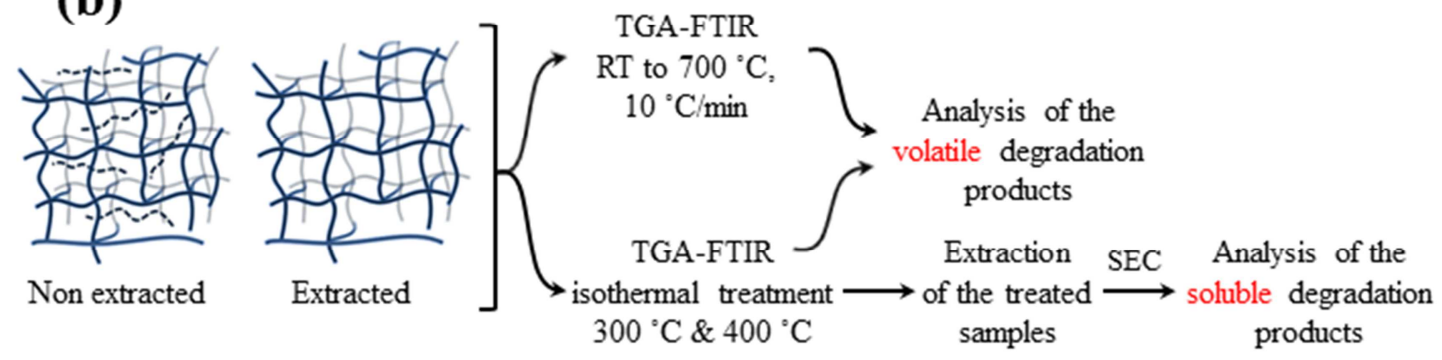

Fig. 1. (a) Hydrosilylation reaction scheme used to synthesize the silicone elastomers with different stoichiometric ratios. (b) The experimental procedure scheme was designed to investigate the thermal degradation behavior of the silicone elastomers, before and after removal of the sol fraction by extraction.

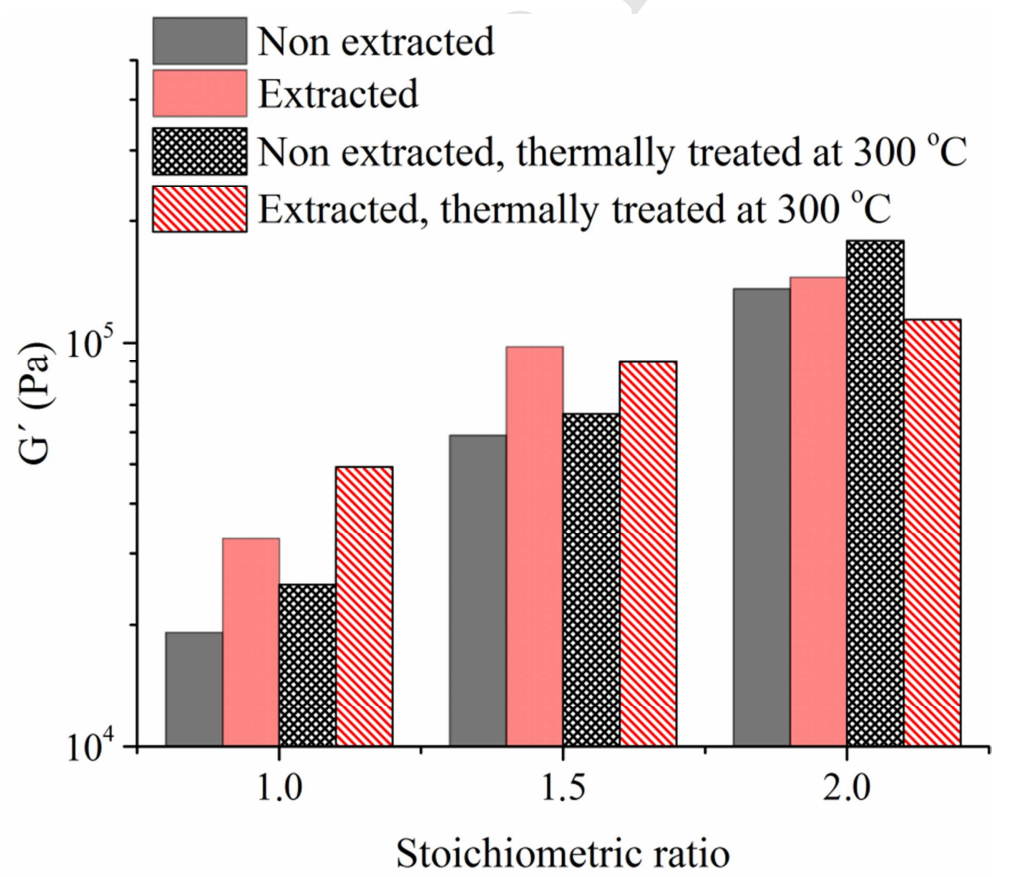


Fig. 2. Storage moduli $\mathrm{G}^{\prime}$ (recorded at $1 \mathrm{~Hz}$ ) of the silicone elastomers, before and after extraction, and before and after isothermal treatment at $300^{\circ} \mathrm{C}$.

\subsection{Thermal degradation behavior and mechanisms}

Thermogravimetric analysis was performed from room temperature to $700^{\circ} \mathrm{C}$ under a nitrogen atmosphere, to inspect the general thermal degradation behavior of the silicone elastomers, before and after removing the sol fraction by extraction. TGA data listed in Table S2 indicate an increase in thermal stability induced by the removal of the sol fraction, since the onset of degradation for all the extracted silicone elastomers shifts toward higher temperatures than the corresponding non-extracted elastomers. Differential thermogravimetric analysis (DTG, Fig. 3 a, b) clearly indicates how the removal of the sol fraction drastically affects the thermal degradation behavior of the samples, which, before extraction, occurred through a two-stage process taking place at different temperatures, depending on the elastomers' stoichiometric imbalances (data shown in Table S2). After extraction, all elastomers degrade thermally via a single-step process occurring in a similar range with a maximum peak temperature of $\sim 500^{\circ} \mathrm{C}$.

Real-time TG-FTIR was used to detect the released volatile degradation products and to evaluate the degradation mechanisms taking place (Fig. 3 c, d). FTIR spectra, 2D, and 3D TG-FTIR plots are illustrated in Fig. S1, S2, and S3, and it is observed that for all the elastomers no volatiles were detected below $340^{\circ} \mathrm{C}$. The maximum release rate was reached at $\sim 450^{\circ} \mathrm{C}$, and the main products detected were mixtures of cyclosiloxanes and low molecular weight linear siloxanes (corresponding to wavelengths of 2965, 1266, 1084, 1023, and $\left.808 \mathrm{~cm}^{-1}\right)$ and methane $\left(3011 \mathrm{~cm}^{-1}\right)$ [35]. These volatile products arise from two main PDMS degradation mechanisms, namely a molecular and a radical mechanism, respectively

(Fig. S5). The former involves the molecular splitting of cyclic oligomers in which the 
formation of an intramolecular transition state is the rate-determining step, while the radical mechanism takes place through homolytic $\mathrm{Si}-\mathrm{CH}_{3}$ bond scission followed by hydrogen abstraction, which eventually leads to the formation of methane [33].

(a)

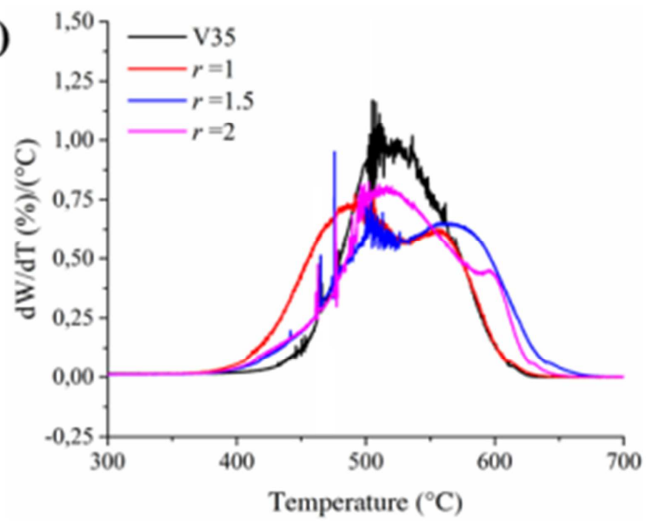

(c)

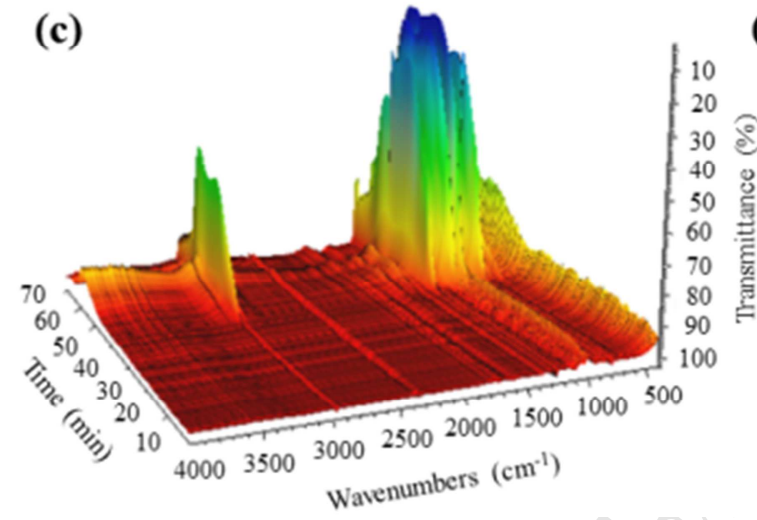

(b)

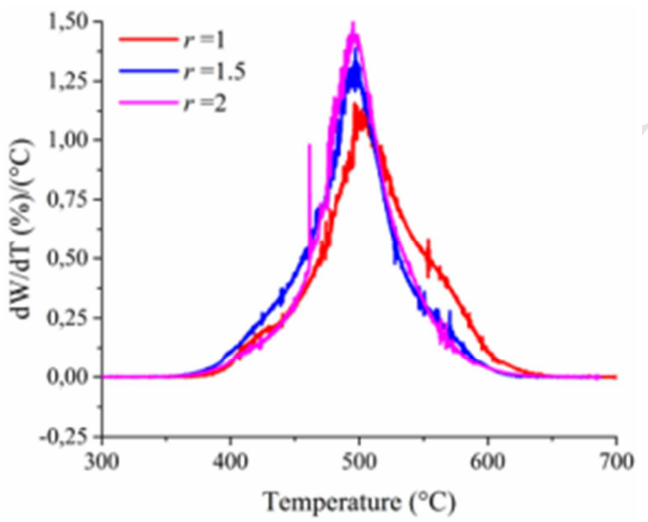

(d)

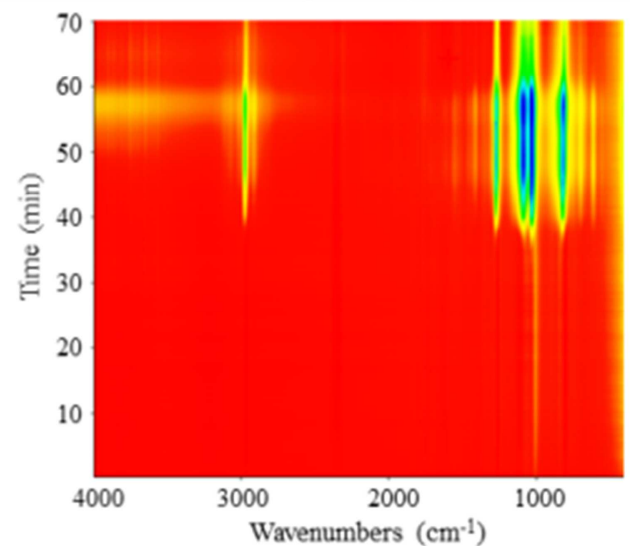

Fig. 3. First derivative of the weight loss curves as a function of the temperature of linear vinyl PDMS (V35) and silicone elastomers, before (a) and after (b) solvent extraction. 3D (c) and 2D (d) TG-FTIR spectra of pyrolysis products of the extracted silicone elastomer $\mathrm{r}=1$ recorded during TG analysis.

\subsection{Isothermal treatment}

Long-term isothermal treatment (12 hours) of the silicone elastomers was performed, in order to collect and analyze the degradation products and to compare the effect of degradation on networks with different structures. Two reference temperatures were chosen, namely 300 and 
$400^{\circ} \mathrm{C}$, since previous results anticipated how the two temperatures induce low and high degrees of volatilization, respectively.

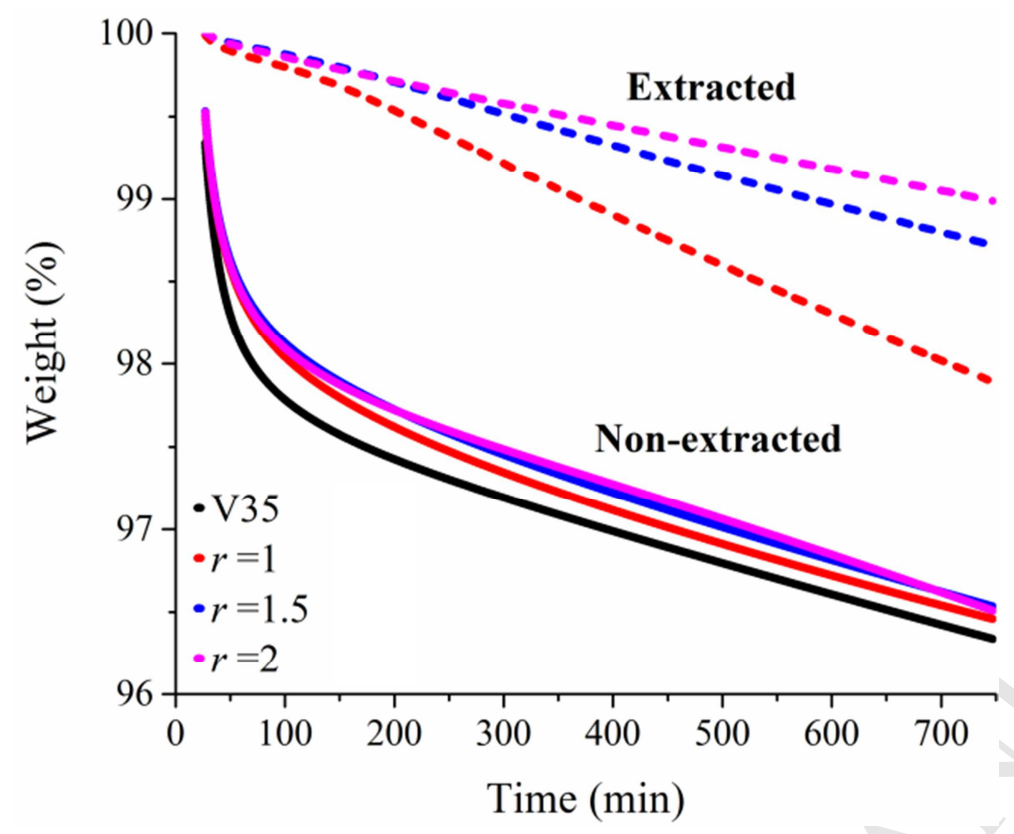

Fig. 4. Weight loss curves of linear polymer V35, non-extracted, and extracted silicone elastomers during the isothermal treatment at $300^{\circ} \mathrm{C}$.

Weight loss curves of the non-extracted and extracted elastomers, obtained from the isothermal treatment at $300^{\circ} \mathrm{C}$, are illustrated in Fig. 4. Results indicate a different degradation pattern for extracted and non-extracted elastomers, but in both cases, a low extent of volatilization was observed, as anticipated by the experimental design. Extracted elastomers showed higher thermal stability than non-extracted elastomers, as indicated by the higher values of residual weights after 12 hours of thermal treatment (Fig. S10). The nonextracted networks and the linear PDMS (V35) show the same degradation trend, characterized by an initial sharp drop in weight followed by a steady and slow decrease. Interestingly, crosslinking of the pure PDMS (V35) was observed after thermal treatment at $300^{\circ} \mathrm{C}$, which can possibly be explained as a result of spontaneous thermal radical oligomerization involving the vinyl groups. Based on the observations, it can be assumed that 
long-term thermal treatment at $300^{\circ} \mathrm{C}$ of the non-extracted elastomers affects the sol fraction, which is mainly composed of linear PDMS (V35). Both crosslinking reactions involving the sol fraction as well as post-curing through the evaporation of volatiles may explain the slight increase in the shear storage moduli $\left(\mathrm{G}^{\prime}\right)$ of the non-extracted elastomers recorded after thermal treatment (Fig. 2).

In contrast, the extracted elastomers showed significantly different behavior. The residual weight recorded after thermal treatment followed a clear trend and increased from the elastomer with $r=1$ towards $r=1.5$ and 2, proving that crosslinking density has a significant beneficial effect on thermal stability. It was also observed that the elastomer with the lowest crosslinking density—and thus the higher amount of dangling chains—-degraded faster compared to the elastomers with $r=1.5$ and 2. A plausible explanation for this would be that for extracted elastomers, thermal degradation by random chain scission involves dangling chains, since the sol fraction is absent. Linear viscoelasticity measurements are consistent with this hypothesis, since a significant increase in $\mathrm{G}^{\prime}$ was observed for the extracted sample with $r=1$, suggesting that the increase in hardness is due to the cleavage of the dangling chains by degradation (Fig. 2). Soluble degradation products resulting from the thermal treatment of the elastomers were collected by solvent extraction and analyzed subsequently by size exclusion chromatography. Data show that the weight average molecular weight of the soluble degradation products decreases in line with the increasing stoichiometric ratio of the elastomers (Table S5). All the discussed outcomes suggest that silicone elastomers degrade thermally following a hierarchical trend, depending on the degree of PDMS chain mobility. Therefore, thermal degradation involves first unreacted PDMS chains (sol fraction), second pendant structures, which are crosslinked to the network by one of the functional ends (dangling chains), and, eventually, the elastically active network chains, which are crosslinked at both ends to the network. 
Isothermal treatment at $400^{\circ} \mathrm{C}$ (Fig. 5) resulted in a considerably high extent of silicone elastomer volatilization. Removing the sol fraction induced an increase in thermal stability for all elastomers, since the extracted samples showed higher residual weights than for the non-extracted samples, as also observed after thermal treatment at $300^{\circ} \mathrm{C}$ (Fig. S10).

Nevertheless, residual weight decreases from the elastomer with $r=1$ towards $r=1.5$ and 2 , meaning that highly crosslinked networks possess lower thermal stability than networks with lower crosslinking density. TG-FTIR was used to detect the volatiles released during the isothermal treatment of the elastomers (FTIR spectra and 2D plots are illustrated in Fig. S8 and S9). Analysis of the data reveals that for all elastomers, the volatiles reached the maximum intensity of absorption at an early stage (after $\sim 40$ minutes) and then started decreasing gradually. The extent of volatilization over time increases in line with the increasing stoichiometric ratio (and thereby crosslinking density) of the elastomers. While no volatiles were detected at the end of the thermal treatment of elastomers with $r=1$, a significant absorption peak intensity was still detected at the end of the thermal treatment of the elastomer with $r=2$. Reported findings on the thermal degradation behavior of PDMS networks with different structural elements may be of relevance to other polymer networks with similar structures, given the common use of PDMS elastomers as model materials in network theory [34].
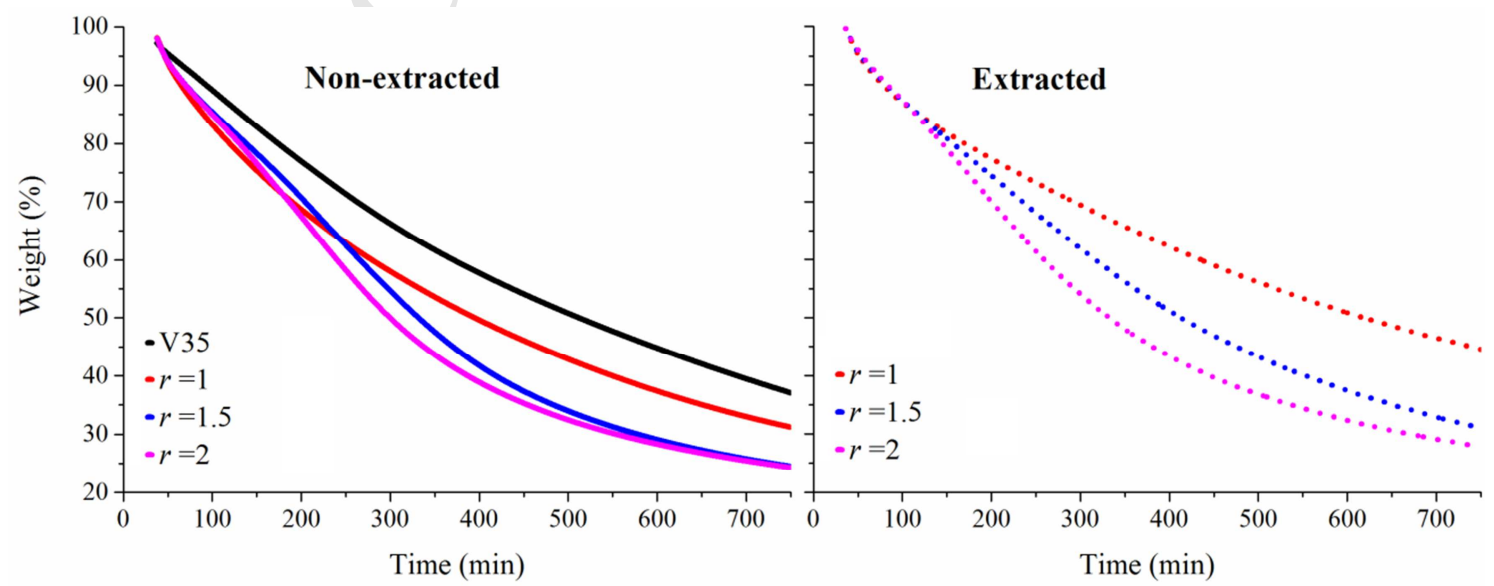
Fig. 5. Weight loss curves of V35 and non-extracted and extracted silicone elastomers during isothermal treatment at $400^{\circ} \mathrm{C}$.

\section{CONCLUSIONS}

In this work, we present a cheap and facile way of boosting the thermal stability of silicone networks that does not involve adding fillers or chemical modification. It is established that the reliability and performance of silicone elastomers used in high-temperature applications are affected strongly by the stoichiometric imbalance used to synthesize the network. Our results prove that an overall improvement in the thermal stability of silicone elastomers can be achieved simply by removing the sol fraction. Long-term isothermal treatment of silicone elastomers was performed at two reference temperatures, namely 300 and $400^{\circ} \mathrm{C}$. At $300^{\circ} \mathrm{C}$, thermal degradation of silicone elastomers involves the sol fraction, but after removing it by extraction, the thermal stability of the elastomers increases in line with increasing crosslinking density, since thermal degradation mainly affects the dangling chains. In contrast, at a higher temperature $\left(400^{\circ} \mathrm{C}\right)$, enhanced thermal stability and reduced volatilization can be achieved by synthetizing silicone elastomers with low crosslinking density. The results of this work can be used to guide the preparation of robust silicone elastomers for high-temperature applications, but they are also meant to have an impact on both the scientific and the industrial level. 


\section{ASSOCIATED CONTENT}

Supporting Information. 2D and 3D TG-FTIR plots, size exclusion chromatography data, and linear viscoelasticity measurements.

\section{AUTHOR INFORMATION}

\section{Corresponding Author}

*E-mail: al@kt.dtu.dk

\section{Author Contributions}

The manuscript was written through the contributions of all authors. All authors have given approval to the final version of the manuscript.

\section{Funding Sources}

The authors acknowledge funding from Villum Fonden and The Independent Research Fund Denmark.

\section{Notes}

The authors have no competing interests to declare.

\section{ACKNOWLEDGMENT}

The authors acknowledge Søren Hvilsted for his suggestions with respect to synthetic strategy.

\section{REFERENCES}

[1] S. Park, K. Mondal, R.M. Treadway, V. Kumar, S. Ma, J.D. Holbery, M.D. Dickey, ACS Appl. Mater. Interfaces 10 (2018) 11261-11268.

[2] G. Zhan, Z. Ye, X. Dong, H. Marvi, O. Erin, W. Hu, M. Sitti, PNAS 41 (2016) 6007- 
6015.

[3] T.P. Tomo, M. Regoli, A. Schmitz, L. Natale, H. Kristanto, S. Somlor, L. Jamone, G. Metta, S. Sugano, IEEE Robot. Autom. Lett. 3 (2018) 2584-2591.

[4] S.J. Benight, C. Wang, J.B.H. Tok, Z. Bao, Prog. Polym. Sci. 38 (2013) 1961-1977.

[5] H. Keum, M. Mccormick, P. Liu, Y. Zhang, F.G. Omenetto, Science 333 (2011) 838843.

[6] J. Li, L. Liang, X. Liu, H. Ma, J. Song, Y. Wei, Int. J. Appl. Mech. 10 (2018) 1850029.

[7] C. Emersic, R. Lowndes, I. Cotton, S. Rowland, R. Freer, IEEE Trans. Dielectr. Electr. Insul. 24 (2017) 2986-2994.

[8] R. Yoda, J. Biomater. Sci. Polym. Ed. 9 (1998) 561-626.

[9] J.C. McDonald, G.M. Whitesides, Acc. Chem. Res. 35 (2002) 491-499.

[10] C. Liu, Adv. Mater. 19 (2007) 3783-3790.

[11] S.C.B. Mannsfeld, B.C. Tee, R.M. Stoltenberg, C.V.H. Chen, S. Barman, B.V.O. Muir, A.N. Sokolov, C. Reese, Z. Bao, Nat. Mater. 9 (2010) 859-864.

[12] J. Maas, C. Graf, Smart. Mater. Struct. 21 (2012) 064006.

[13] K. Chenoweth, S. Cheung, A.C.T. Van Duin, W.A.G. Iii, E.M. Kober, J. Am. Chem. Soc. (2005) 7192-7202.

[14] S. Hamdani, C. Longuet, D. Perrin, J.-M. Lopez-cuesta, F. Ganachaud, Polym. Degrad. Stab. 94 (2009) 465-495.

[15] N.S. Tomer, Open J. Org. Polym. Mater. 02 (2012) 13-22. 
[16] J.S. Kim, S. Yang, B.S. Bae, Chem. Mater. 22 (2010) 3549-3555.

[17] S. Hanada, M. Miyamoto, N. Hirai, L. Yang, Y. Ohki, High Volt. 2 (2017) 92-101.

[18] K. George, B.P. Panda, S. Mohanty, S.K. Nayak, Polym. Adv. Technol. 29 (2018) 821.

[19] A.L. Larsen, K. Hansen, O. Hassager, A. Bach, S. Ndoni, M. Jørgensen, Macromolecules 36 (2003) 10063-10070.

[20] S.M.G. Frankær, M.K. Jensen, A.G. Bejenariu, A.L. Skov, Rheol. Acta 51 (2012) 559567.

[21] D.R. Miller, C.W. Macosko, Macromolecules 95 (1972) 206-211.

[22] A.L. Skov, L. Yu, Adv. Eng. Mater. 1700762 (2018) 1-21.

[23] G. Camino, S.M. Lomakin, M. Lageard, Polymer (Guildf). 43 (2002) 2011-2015.

[24] C. Camino, S.M. Lomakin, M. Lazzari, Polymer (Guildf). 42 (2001) 2395-2402.

[25] N. Grassie, I.G. Macfarlane, Eur. Polym. J. 14 (1978) 875-884.

[26] W. Fang, X. Zeng, X. Lai, H. Li, W. Chen, Y. Zhang, Thermochim. Acta 605 (2015) 28-36.

[27] C.J. Yeh, M. Dowland, R.G. Schmidt, K.R. Shull, J. Polym. Sci. Part B Polym. Phys. 54 (2016) 263-273.

[28] S. Zakaria, F.B. Madsen, A.L. Skov, Polym. - Plast. Technol. Eng. 56 (2017) 83-95.

[29] M.A. Brook, H.U. Saier, J. Schnabel, K. Town, M. Maloney, Ind. Eng. Chem. Res. 46 (2007) 8796-8805. 
[30] S. Hamdani, C. Longuet, J.-M. Lopez-Cuesta, F. Ganachaud, Polym. Degrad. Stab. 95 (2010) 1911-1919.

[31] K. Hayashida, S. Tsuge, H. Ohtani, Polymer (Guildf). 44 (2003) 5611-5616.

[32] H. Li, S. Tao, Y. Huang, Z. Su, J. Zheng, Compos. Sci. Technol. 76 (2013) 52-60.

[33] Y. Liu, Y. Shi, D. Zhang, J. Li, G. Huang, Polymer (Guildf). 54 (2013) 6140-6149.

[34] F. Campise, D.C. Agudelo, R.H. Acosta, M.A. Villar, E.M. Vallés, G.A. Monti, D.A. Vega, Macromolecules 50 (2017) 2964-2972.

[35] W. Chen, X. Zeng, X. Lai, H. Li, W. Fang, T. Liu, Thermochim. Acta 632 (2016) 1-9. 
- Silicone elastomers with varying cross-linking densities were investigated through thermogravimetric analysis.

- Network reactant stoichiometry was shown to strongly affect thermal degradation behaviour.

- Silicone polymers within the elastomer degrade thermally hierarchically, with most mobile polymers degrading the first.

- Removal of the sol fraction therefore leads to an overall increase in the thermal stability. 